\title{
Synthesis of a Triple-Responsive Double Hydrophilic Block Copolymer Prodrug Using a Reducible RAFT-ATRP Double-Head Agent
}

Lu Sun, ${ }^{\text {a,b }}$ Yang Zhou, ${ }^{\mathrm{b}}$ Xufeng Zhou, ${ }^{\mathrm{b}}$ Liwei Ma, ${ }^{\mathrm{b}}$ Baoyan Wang, ${ }^{\mathrm{b}}$ Cuiyun $\mathrm{Yu},{ }^{\mathrm{a},{ }^{*}}$ and Hua Wei ${ }^{\mathrm{a}, \mathrm{b}, *}$

${ }^{\text {a}}$ Hunan Province Cooperative Innovation Center for Molecular Target New Drug

Study \& Department of Pharmacy and Pharmacology, University of South China, Hengyang, 421001, China.

${ }^{\mathrm{b}}$ State Key Laboratory of Applied Organic Chemistry, Key Laboratory of Nonferrous Metal Chemistry and Resources Utilization of Gansu Province, and College of Chemistry and Chemical Engineering, Lanzhou University, Lanzhou, Gansu 730000, China

*Corresponding authors

E-mail addresses: weih@1zu.edu.cn, huawei_usc@163.com (H. Wei) or yucuiyunusc@hotmail.com (C. Yu) 
List of contents ( 21 pages including 11 Figures, 1 Scheme and 1 Table)

1. Materials and Experimental section

\section{Characterization}

3. Figure S1-S11

4. Scheme $S 1$

5. Table S1 


\section{Materials and Experimental section}

$\mathrm{N}$-(2-Hydroxypropyl) methacrylamide (HPMA) was prepared according to the reported procedures. ${ }^{1-2}$ Ethyl glycinate methacrylamide $\quad$ (EGMA) was synthesized as previously reported. ${ }^{3} \mathrm{~N}$-Isopropyl acrylamide (NIPAAm, J\&K, 99\%) was purified by recrystallization twice from n-hexane (Rionlon (Tianjin), 97\%). 2,2'-Azoisobutylacetamide (AIBN, J\&K, 99\%) was recrystallized twice from ethanol (Rionlon (Tianjin), 95\%). 1,4-dioxane (Rionlon(Tianjin), 99.5\%) was distilled under reduced pressure to remove the inhibitor. 2-Hydroxyethyl-2'-(bromoisobutyryl)ethyl disulfide double-head initiator (OH-SS-iBuBr) was prepared according to literature. ${ }^{4}$ Tris(2-aminoethyl)amine (Me 6 TREN) was prepared according to literature. ${ }^{5}$ Propargyl acrylate (J\&K, 98\%). 4-Cyanopentanoic acid dithiobenzoate (CPADB, Aldrich, 97\%), doxorubicin hydrochloride (DOX $\cdot \mathrm{HCl}, 98 \%)$, hydrazine hydrate aqueous solution (J\&K, 80\%), tetrahydrofuran (THF, 99\%), anhydrous ethyl ether (99.0\%), anhydrousmethanol (99.5\%) and all the other reagents and solvents were purchased from J\&K, Sigma-Aldrich or Rionlon (Tianjin) and used as received. $\mathrm{P}$ (HPMA-st-(EGMA-DOX))-b-P (NIPAAm) (HE-N) was synthesized according to our previous report. ${ }^{6}$

\section{Synthesis of double-head agent (CPADB-SS-iBuBr)}

CPADB (1 g, $3.5 \mathrm{mmol})$, DCC (0.8 g, $3.9 \mathrm{mmol})$ and DMAP (0.04 g, $0.35 \mathrm{mmol})$ were dissolved in anhydrous DCM $(50 \mathrm{~mL})$, and the solution was cooled to $0{ }^{\circ} \mathrm{C}$ 
under the condition of $\mathrm{N}_{2}$. OH-SS-iBuBr $(1.2 \mathrm{~g}, 3.9 \mathrm{mmol})$ in $20 \mathrm{~mL}$ DCM was added dropwise to the reaction mixture. The solution was further stirred overnight after stirring for $30 \mathrm{~min}$ in an ice bath. The precipitated dicyclohexyl urea (DCU) formed during the reaction was removed by vacuum filtration. Subsequently, the solvent was removed by rotary evaporation, and the product was purified by column chromatography with mixtures of ethyl acetate/hexane $(1 / 3 \mathrm{v} / \mathrm{v})$. The product was isolated by evaporation of the solvents and further dried in a vacuum oven to form a red oily residue. Yield $=44.5 \% .{ }^{1} \mathrm{H} \mathrm{NMR}\left(\mathrm{CDCl}_{3}, \mathrm{ppm}\right)$ 7.93-7.37 $\left(\mathrm{m}, 5 \mathrm{H}, \mathrm{C}_{6} H_{5}\right), 4.44$ (t, 2H, -(O) $\left.\mathrm{COCH}_{2} \mathrm{CH}_{2}-\mathrm{SS}\right), 4.39$ (t, 2H, SS- $\left.\mathrm{CH}_{2} \mathrm{CH}_{2} \mathrm{OC}(\mathrm{O})-\right), 2.99-2.91$ (t, 4H, $\left.-\mathrm{CH}_{2} \mathrm{CH}_{2}-\mathrm{SS}-\mathrm{CH}_{2} \mathrm{CH}_{2}-\right), 2.72$ (t, $\left.2 \mathrm{H},-(\mathrm{CN})\left(\mathrm{CH}_{3}\right) \mathrm{CCH}_{2} \mathrm{CH}_{2} \mathrm{COO}-\right), 2.5-2.4$ (m, $2 \mathrm{H}$, $\begin{array}{llll}\left.-(\mathrm{CN})\left(\mathrm{CH}_{3}\right) \mathrm{CCH}_{2} \mathrm{CH}_{2} \mathrm{COO}-\right), & 1.94 \quad \text { (s, }\end{array}$ $\left.-(\mathrm{CN})\left(\mathrm{CH}_{3}\right) \mathrm{CCH}_{2} \mathrm{CH}_{2} \mathrm{COOCH}_{2} \mathrm{CH}_{2} \mathrm{SSCH}_{2} \mathrm{CH}_{2} \mathrm{O}(\mathrm{O}) \mathrm{CC}\left(\mathrm{CH}_{3}\right)_{2} \mathrm{Br}\right)$.

\section{Synthesis of P(HPMA-st-EGMA)-SS-iBuBr by RAFT polymerization}

P(HPMA-st-EGMA) statistical copolymers were prepared by RAFT polymerization in $\mathrm{MeOH} / 1$,4-dioxane using CPADB-SS-iBuBr as a CTA. Typically, CPADB-SS-iBuBr (12.69 mg, $0.0225 \mathrm{mmol})$, HPMA (643.5 mg, $4.5 \mathrm{mmol})$, EGMA (384.75 mg, $2.25 \mathrm{mmol})$ and AIBN (1.26 mg, $0.0075 \mathrm{mmol})$ were dissolved in $3 \mathrm{~mL}$ $\mathrm{MeOH} / 1,4$-dioxane $(1 / 2 \mathrm{v} / \mathrm{v})$, and then transferred to a $10 \mathrm{~mL}$ Schlenk flask. The solution was degassed by three freeze-pump-thaw cycles, and sealed under vacuum followed by immersing in an oil bath preheated at $70{ }^{\circ} \mathrm{C}$ to start the polymerization. After $1 \mathrm{~h} 15 \mathrm{~min}$, the polymerization was quenched by immersing the flask in liquid 
nitrogen. The polymer solution, after thawing, was diluted with $\mathrm{MeOH}$, and precipitated in anhydrous diethyl ether. The product was further purified by extensive dialysis (MWCO 3500) against distilled water for $24 \mathrm{~h}$, and collected by freeze-drying.

\section{Synthesis of Alkyne-P(HPMA-st-EGMA)-SS-iBuBr}

To a $25 \mathrm{~mL}$ Schlenk flask equipped with a magnetic stirrer, P(HPMA-st-EGMA)-SS-iBuBr (100 mg) dissolved in $10 \mathrm{~mL} \mathrm{MeOH/1,4-dioxane} \mathrm{(1/2}$ v/v), was added. After three freeze-pump-thaw cycles, n-butylamine $(120.76 \mu \mathrm{L}$, $1.216 \mathrm{mmol}, 100 \mathrm{eq})$, and propargyl acrylate (136.32 $\mu \mathrm{L}, 1.216 \mathrm{mmol}, 100 \mathrm{eq})$ were introduced into the flask under $\mathrm{N}_{2}$. Finally, the reaction mixture was degassed with another three freeze-pump-thaw cycles and then sealed followed by immersing the flask into an oil bath at $\mathrm{rt}$. for $12 \mathrm{~h}$. The final mixture was precipitated in anhydrous diethyl ether. The product was further purified by extensive dialysis (MWCO 3500) against distilled water for $24 \mathrm{~h}$, and collected by freeze-drying.

\section{Synthesis of Alkyne-P(HPMA-st-EGMA)-SS-P(NIPPAm)}

Alkyne-P(HPMA-st-EGMA)-SS-P(NIPPAm) was synthesized by ATRP using Alkyne-P(HPMA-st-EGMA)-SS-iBuBr as the initiator and $\mathrm{CuBr} / \mathrm{Me}_{6} \mathrm{TREN}$ as the catalyst. Typically, a solution of Alkyne-P(HPMA-st-EGMA)-SS-iBuBr (47.76 mg), NIPAAm (217.54 mg, $1.925 \mathrm{mmol}), \mathrm{Me}_{6} \mathrm{TREN}(1.47 \mu \mathrm{L}, 0.0055 \mathrm{mmol})$ in $3.85 \mathrm{~mL}$ water/isopropanol (1/9 v/v) was added into a $10 \mathrm{~mL}$ Schlenk flask. After three 
freeze-pump-thaw cycles, $\mathrm{CuBr}(0.79 \mathrm{mg}, 0.0055 \mathrm{mmol})$ was introduced into the flask under $\mathrm{N}_{2}$. Finally, the reaction mixture was degassed with another three freeze-pump-thaw cycles and then sealed followed by immersing the flask into an oil bath at $45{ }^{\circ} \mathrm{C}$ for $12 \mathrm{~h}$. The polymerization was quenched by immersing the flask in the liquid nitrogen and diluted with THF, and the final mixture was precipitated in anhydrous diethyl ether. The product was further purified by extensive dialysis (MWCO 3500) against distilled water for $24 \mathrm{~h}$, and collected by freeze-drying.

\section{Synthesis of Alkyne-P(HPMA-st-(EGMA-NH-NH2))-SS-P(NIPPAm)}

Typically, a solution of Alkyne-P(HPMA-st-EGMA)-SS-P(NIPPAm) (70 mg) and hydrazine hydrate $(125 \mu \mathrm{L}, 2.06 \mathrm{mmol}, 50 \mathrm{eq})$ in $3 \mathrm{~mL}$ anhydrous methanol was added into $10 \mathrm{~mL}$ Schlenk flask. The flask was immersed into an oil bath at rt. for 24 h. the product was further purified by extensive dialysis (MWCO 3500) against distilled water for $24 \mathrm{~h}$, and collected by freeze-drying. The content of hydrazide was determined by ${ }^{1} \mathrm{H}$ NMR.

\section{Synthesis of Alkyne-P(HPMA-st-(EGMA-DOX))-SS-P(NIPPAm)}

Typically, a solution of Alkyne-P(HPMA-st-(EGMA-NH-NH 2$)$ )-SS-P(NIPPAm) (15 $\mathrm{mg}), \mathrm{DOX} \cdot \mathrm{HCl}(7.67 \mathrm{mg}, 0.013 \mathrm{mmol})$ and a drop of acetic acid in $3 \mathrm{~mL}$ anhydrous methanol was added into $10 \mathrm{~mL}$ Schlenk flask. The flask was sealed and the reaction mixture was stirred in the dark at rt. for $48 \mathrm{~h}$. the product was further purified by extensive dialysis (MWCO 3500) against anhydrous methanol for $24 \mathrm{~h}$, followed by 
further dialysis (MWCO 3500) against distilled water for another $24 \mathrm{~h}$, and collected by freeze-drying. The amount of drug conjugated was determined by measuring the absorbance of DOX on a UV-vis spectrometer at $499 \mathrm{~nm}$ based on a previously established calibration. The Drug loading content (DLC) was calculated using the following equation:

DLC $(\%)=\frac{\text { weight of DOX in prodrug }}{\text { weight of prodrug }} \times 100 \%$

\section{Synthesis of (2-Azidoethyl) benzene}

(2-Azidoethyl) benzene was synthesized according to lectures. ${ }^{7-9}$ To a stirred solution of (2-bromoethyl) benzene $(1 \mathrm{~g}, 20.0 \mathrm{mmol})$ in $\mathrm{DMF}(10.0 \mathrm{~mL})$ was added $\mathrm{NaN}_{3}$ ( $3.90 \mathrm{~g}, 60.0 \mathrm{mmol})$. Then the reaction mixture was warmed to $75^{\circ} \mathrm{C}$ and stirred for 8 $\mathrm{h}$, then cooled to room temperature and quenched with water $(3 \mathrm{~mL})$. The mixture was extracted with ethyl acetate $(13 \mathrm{ml} \times 3)$, and the combined organic phase was washed with water $(13 \mathrm{ml} \times 4)$ and brine $(13 \mathrm{ml})$, dried over $\mathrm{Na}_{2} \mathrm{SO}_{4}$. The product was isolated by evaporation of the solvents to form a light yellow residue. Yield $=82 \%$. ${ }^{1} \mathrm{H}$ NMR $\left(\mathrm{CDCl}_{3}, \mathrm{ppm}\right)$ 7.35-7.18 (m, 5H, $\left.\mathrm{C}_{6} \boldsymbol{H}_{5}\right), 3.51\left(\mathrm{t}, 2 \mathrm{H},-\mathrm{CH}_{2} \mathrm{CH}_{2} \mathrm{~N}_{3}\right), 2.91(\mathrm{t}$, $\left.2 \mathrm{H},-\mathrm{CH}_{2} \mathrm{CH}_{2} \mathrm{~N}_{3}\right)$.

\section{Synthesis of Phenyl-P(HPMA-st-EGMA)-SS-P(NIPPAm)}

Typically, a solution of Alkyne-P(HPMA-st-EGMA)-SS-P(NIPPAm) (17.13 mg), (2-Azidoethyl) benzene (2.52 mg, $0.017 \mathrm{mmol}, 30 \mathrm{eq})$, PMDETA (0.19 $\mu 1,0.0011$ 
mmol) in $1 \mathrm{ml}$ DMF was added into a $10 \mathrm{ml}$ Schlenk flask. After three freeze-pump-thaw cycles, $\mathrm{CuBr}(0.16 \mathrm{mg}, 0.0011 \mathrm{mmol})$ was introduced into the flask under $\mathrm{N}_{2}$. Finally, the reaction mixture was degassed with another three freeze-pump-thaw cycles and then sealed followed by immersing the flask into an oil bath at $45{ }^{\circ} \mathrm{C}$ for $24 \mathrm{~h}$. The polymerization was quenched by immersing the flask in the liquid nitrogen and diluted with THF, and the final mixture was precipitated in anhydrous diethyl ether. The product was further purified by extensive dialysis (MWCO 3500) against distilled water for $24 \mathrm{~h}$, and collected by freeze-drying.

\section{Stability and degradation of micelle prodrugs}

The prodrug was dissolved in four different release media of phosphate buffer (PBS, $\mathrm{pH} 7.4,10 \mathrm{mmol})$ with and without $10 \mathrm{mM} \mathrm{GSH}$, citrate buffer (pH 5.5, $10 \mathrm{mmol})$ with and without $10 \mathrm{mM}$ GSH. Then the prodrug solution was introduced into $5 \mathrm{~mL}$ microcentrifuge tubes that were kept in a horizontal laboratory shaker thermostated at a constant temperature of $37{ }^{\circ} \mathrm{C}$ and with a stirring speed of $120 \mathrm{rpm}$. At predetermined time intervals, the mean hydrodynamic size and size distribution (polydispersity index, PDI) of the prodrug micelles were examined by DLS.

\section{In vitro drug release study}

The solution of prodrug in phosphate buffer (PBS, $\mathrm{pH} 7.4,10 \mathrm{mM}$ ) was split in equal volumes into four dialysis tubes with a MWCO of $3.5 \mathrm{kDa}$, which were then immersed in a Falcon tube containing $25 \mathrm{~mL}$ of four different release media of 
phosphate buffer (PBS, pH 7.4, $10 \mathrm{mmol}$ ), citrate buffer ( $\mathrm{pH} 5.5,10 \mathrm{mmol}$ ), phosphate buffer (PBS, pH 7.4, $10 \mathrm{mmol}$ ) with $10 \mathrm{mM} \mathrm{GSH}$ and citrate buffer (pH 5.5, $10 \mathrm{mmol}$ ) with $10 \mathrm{mM} \mathrm{GSH}$ at $37{ }^{\circ} \mathrm{C}$ with constant shaking (120 rpm). At predetermined time intervals, $3 \mathrm{~mL}$ of release medium was sampled and replenished with equal volume of fresh medium. The samples were determined by measuring the absorbance at $499 \mathrm{~nm}$ with UV-vis spectrometer using a calibration curve obtained from free $\mathrm{DOX} \cdot \mathrm{HCl}$ in the corresponding release buffers. The experiment was performed in quadruplicate for each sample, and the data were presented as mean values.

\section{Cell viability assay}

The in vitro cytotoxicity of various formulations was evaluated by the MTT assay. HeLa cells were seeded in 96-well plates at a plating density of 2500 cells per well in $100 \mu \mathrm{L}$ of complete growth medium and incubated in an incubator maintained at 37 ${ }^{\circ} \mathrm{C}$ and $5 \% \quad \mathrm{CO}_{2}$ environment for $24 \mathrm{~h}$. The sample solutions of Alkyne-P(HPMA 36 -st-(EGMA 18 -DOX 9$)$ )-SS-P(NIPAAm $\left.{ }_{192}\right)$

(HE-SS-N), $\mathrm{P}\left(\mathrm{HPMA}_{38}-s t-\left(\mathrm{EGMA}_{19}-\mathrm{DOX}_{13}\right)\right)-b-\mathrm{P}\left(\mathrm{NIPAAm}_{207}\right) \quad(\mathrm{HE}-\mathrm{N})$ and free DOX were prepared in serial dilutions with sterilized water and then diluted in 10-fold in Opti-MEM medium (Invitrogen). The cells were rinsed once with PBS and incubated with $40 \mu \mathrm{L}$ of the sample solutions with different polymer or DOX concentrations at $37{ }^{\circ} \mathrm{C}$ for $4 \mathrm{~h}$. Cells were next rinsed with PBS and the medium was replaced with 100 $\mu \mathrm{L}$ of culture medium and incubated at $37{ }^{\circ} \mathrm{C}$ and $5 \% \mathrm{CO}_{2}$ for another $20 \mathrm{~h}$. After 
addition of $20 \mu \mathrm{L}$ of MTS reagent to each well, cells were then incubated at $37^{\circ} \mathrm{C}$ and $5 \% \mathrm{CO}_{2}$ for $3 \mathrm{~h}$. The absorbance of each well was measured at a wavelength of 490 nm on a Tecan Safire2 plate reader (Männerdorf, Switzerland). Cell viability for each treatment condition was determined by normalizing to the cells only signal.

\section{Evaluation of cellular uptake by flow cytometry (FCM) analysis}

HeLa cells were seeded in 24-well plates at a density of 140000 cells per well in 1 $\mathrm{mL}$ of complete growth medium and incubated for $24 \mathrm{~h}$ at $37{ }^{\circ} \mathrm{C}$ in $5 \% \mathrm{CO}_{2}$ environment. After the cells were rinsed once with PBS, fresh MEM containing DOX was added to replace the original medium, and the cells with sterilized water were set as a control. The DOX concentration for the solution of free DOX.HCl, HE-SS-N prodrug and HE-N prodrug in MEM was set at $20 \mu \mathrm{g} / \mathrm{mL}$. After incubation for $4 \mathrm{~h}$, the sample solutions were aspirated, and the cells were rinsed twice with PBS. Cells were then harvested by incubation with $200 \mu \mathrm{L}$ of Trypsin-EDTA, followed by resuspension with $1 \mathrm{~mL}$ of complete growth medium. Cells were transferred to 1.5 $\mathrm{mL}$ microcentrifuge tubes and pelleted at $300 \mathrm{~g}$ for $5 \mathrm{~min}$ at $4{ }^{\circ} \mathrm{C}$. The supernatant was aspirated, and the cell pellets were resuspended in $200 \mu \mathrm{L}$ of PBS. Cells were analyzed for uptake of fluorescent polymer using a BD Accuri C6 Plus flow cytometer (BD Biosciences) with an excitation wavelength and emission wavelength of $488 \mathrm{~nm}$ and $595 \mathrm{~nm}$. A minimum of 10000 cells was analyzed each sample with the fluorescence intensity. 


\section{Characterization}

${ }^{1} \mathrm{H}$ NMR spectra were recorded on a JNM-ECS spectrometer at $400 \mathrm{MHZ}$ using $\mathrm{CDCl}_{3}$ and $d_{6}$-DMSO as the solvents, respectively. Specifically, $\mathrm{CDCl}_{3}$ was used for CPADB-SS-iBuBr. $d_{6}$-DMSO was used for P(HPMA $36-s t-$ EGMA $\left._{18}\right)-S S-i B u B r$, Alkyne-P(HPMA ${ }_{36}$-st-EGMA 18$)-S S-i B u B r, \quad$ Alkyne-P(HPMA 36 -st-EGMA 18$)-S S-P$ (NIPPAm 192$)$, and Alkyne-P(HPMA $36-s t-\left(\right.$ EGMA $\left.\left._{18}-\left(\mathrm{NH}_{2} \mathrm{NH}_{2}\right)_{13}\right)\right)-\mathrm{SS}-\mathrm{P}\left(\mathrm{NIPPAm}{ }_{192}\right)$. The average hydrodynamic diameter $\left(D_{\mathrm{h}}\right)$ at various temperatures was measured by dynamic light scattering (DLS) on a Zetasizer (Nano ZS, Malvern, Worcestershire, UK) at a fixed detection angle of $173^{\circ}$. The zeta potential of Alkyne-P(HPMA ${ }_{36}$-st-(EGMA 18 -DOX $\left.\left.{ }_{9}\right)\right)-S S-P\left(N_{I P A A m}{ }_{192}\right)$ micelle prodrugs in distilled water was measured using a Nano-ZS ZEN3600 (Malvern Instruments) at 37 ${ }^{\circ} \mathrm{C}$. The size exclusion chromatography and multi-angle laser light scattering (SEC-MALLS) was carried out to determine the molecular weight and molecular weight distribution of the polymers. SEC using HPLC-grade DMF containing 0.1 $\mathrm{wt} \% \mathrm{LiBr}$ at $60{ }^{\circ} \mathrm{C}$ as the eluent at a flow rate of $1 \mathrm{~mL} / \mathrm{min}$ Tosoh TSK-GEL R-3000 and R-4000 columns (Tosoh Bioscience) were connected in series to a Agilent 1260 series (Agilent Technologies), an interferometric refractometer (Optilab-rEX, Wyatt Technology) and a MALLS device (DAWN EOS, Wyatt Technology). The MALLS detector was operated at a laser wavelength of $690.0 \mathrm{~nm}$. Ultraviolet-visible (UV-vis) absorption of the sample solution was measured on an UV-1780 spectrometer (SHIMADZU, Kyoto, Japan). TEM measurements were carried out on a JNM-2010 instrument operating at an acceleration voltage of $200 \mathrm{keV}$. The polymer solution 
$(0.05 \mathrm{mg} / \mathrm{mL})$ was thermostatted at $37^{\circ} \mathrm{C}$ for $12 \mathrm{~h}$ prior to sample preparation. The TEM samples were made by dropping $10 \mu \mathrm{L}$ of the solution onto a carbon-coated copper grid for $5 \mathrm{~min}$, and the excess solution was slightly blotted up by a filter paper. Thereafter, one drop of phosphotungstic acid solution (PTA, 1\%, pH 6.5) was added onto the copper grid and kept for 5 min for staining. The final grid was dried overnight under ambient environment.

\section{References}

1. Kasuya, Y.; Lu, Z. R.; Kopec`kova', P.; Minko, T.; Tabibi, S. E.; Kopec`ek, J. Synthesis and Characterization of HPMA Copolymer-Aminopropylgeldanamycin Conjugates. J. Control. Release 2001, 74, 203-211.

2. Pan, Y. J.; Li, D.; Jin, S.; Wei, C.; Wu, K. Y.; Guo, J.; Wang, C. C. Folate-Conjugated Poly(N-(2-Hydroxypropyl)-Methacrylamide-co-Methacrylic Acid) Nanohydrogels with pH/Redox Dual-Stimuli Response for Controlled Drug Release. Polym. Chem. 2013, 4, 3545-3553.

3. Zhan, F. X.; Chen, W.; Wang, Z. J.; Lu, W. T.; Cheng, R.; Deng, C.; Meng, F. H.; Liu, H. Y.; Zhong, Z. Y. Acid-Activatable Prodrug Nanogels for Efficient Intracellular Doxorubicin Release. Biomacromolecules 2011, 12, 3612-3620.

4. Sourkohi, B. K.; Cunningham, A.; Zhang, Q.; Oh, J. K. Biodegradable Block Copolymer Micelles with Thiol-Responsive Sheddable Coronas. Biomacromolecules 2011, 12, 3819-3825.

5. Chen, J. C.; Liu, M. Z.; Gong, H. H.; Huang, Y. J.; Chen, C. Synthesis and 
Self-Assembly of Thermoresponsive PEG- $b$-PNIPAM- $b$-PCL ABC Triblock

Copolymer Through the Combination of Atom Transfer Radical Polymerization, Ring-Opening Polymerization, and Click Chemistry. J. Phys. Chem. B 2011, 115, $14947-14955$.

6. Zhou, X. F.; Chang, C.; Zhou, Y.; Sun, L.; Xiang, H; Zhao, S. J.; Ma, L. W.; Zheng,

G. H.; Liu, M. Z.; Wei, H. A Comparison Study to Investigate the Effect of the Drug-loading Site on Its Delivery Efficacy Using Double Hydrophilic Block Copolymer-Based Prodrugs. J. Mater. Chem. B 2017, 5, 4443-4454.

7. Yu, C. J.; Li, R.; Gu, P. M. Intermolecular Schmidt Reaction of Alkyl Azides with Acyl Silanes. Tetrahedron Lett. 2016, 57, 3568-3570.

8.Tesch, M.; Kudruk, S.; Letzel, M.; Studer, A. Orthogonal Click Postfunctionalization of Alternating Copolymers Prepared by Nitroxide-Mediated Polymerization. Chem. Eur. J. 2017, 23, 5915 - 5919.

9. Fabre, B.; Pícha, J.; Vaněk, V.; Selicharová, I.; Chrudinová, M.; Collinsová, M.; Žáková, L.; Buděšínský, M.; J Jiráček, J. Synthesis and Evaluation of a Library of Trifunctional Scaffold-Derived Compounds As Modulators of the Insulin Receptor. ACS Comb. Sci. 2016, 18, 710-722. 

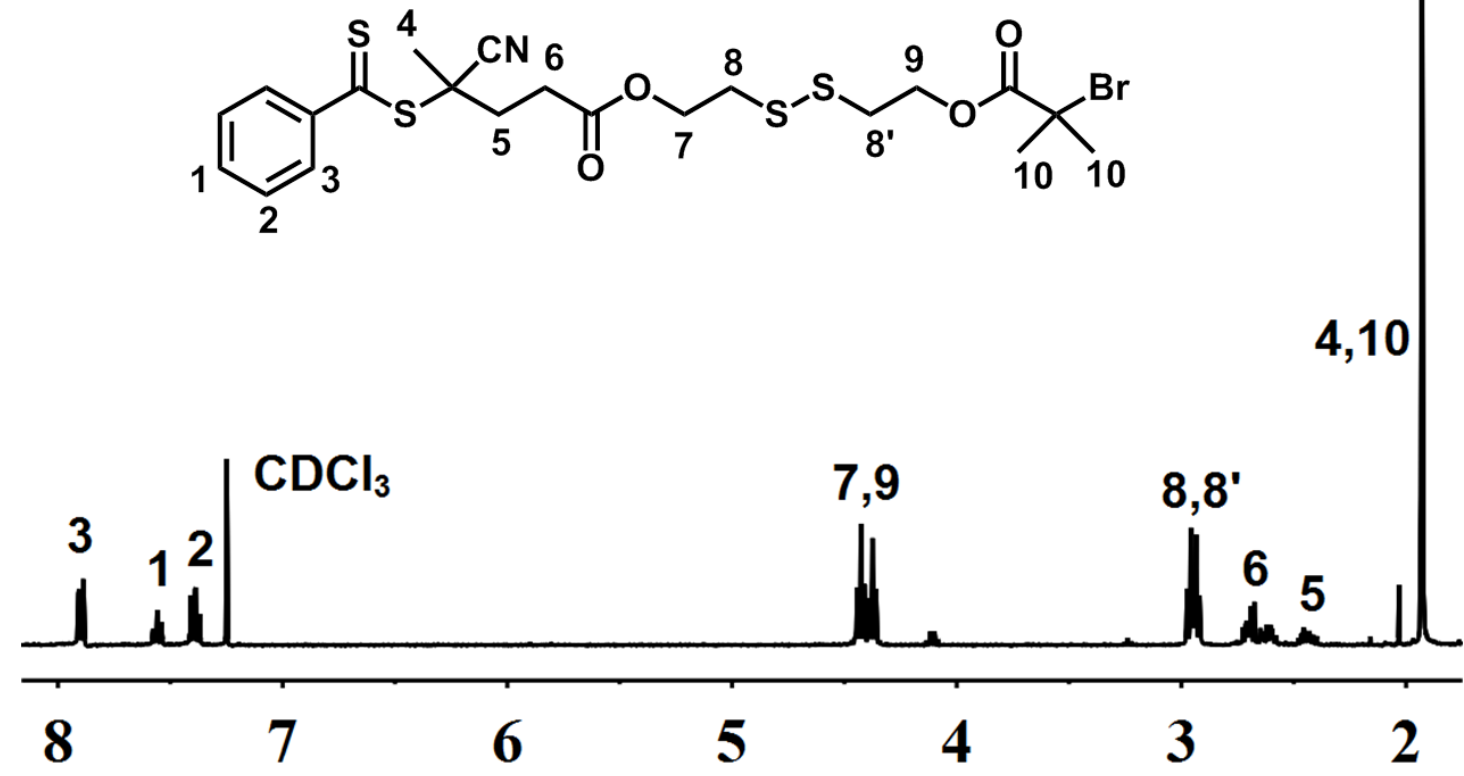

Figure S1. ${ }^{1} \mathrm{H}$ NMR spectrum of CPADB-SS-iBuBr $\left(\mathrm{CDCl}_{3}\right)$.

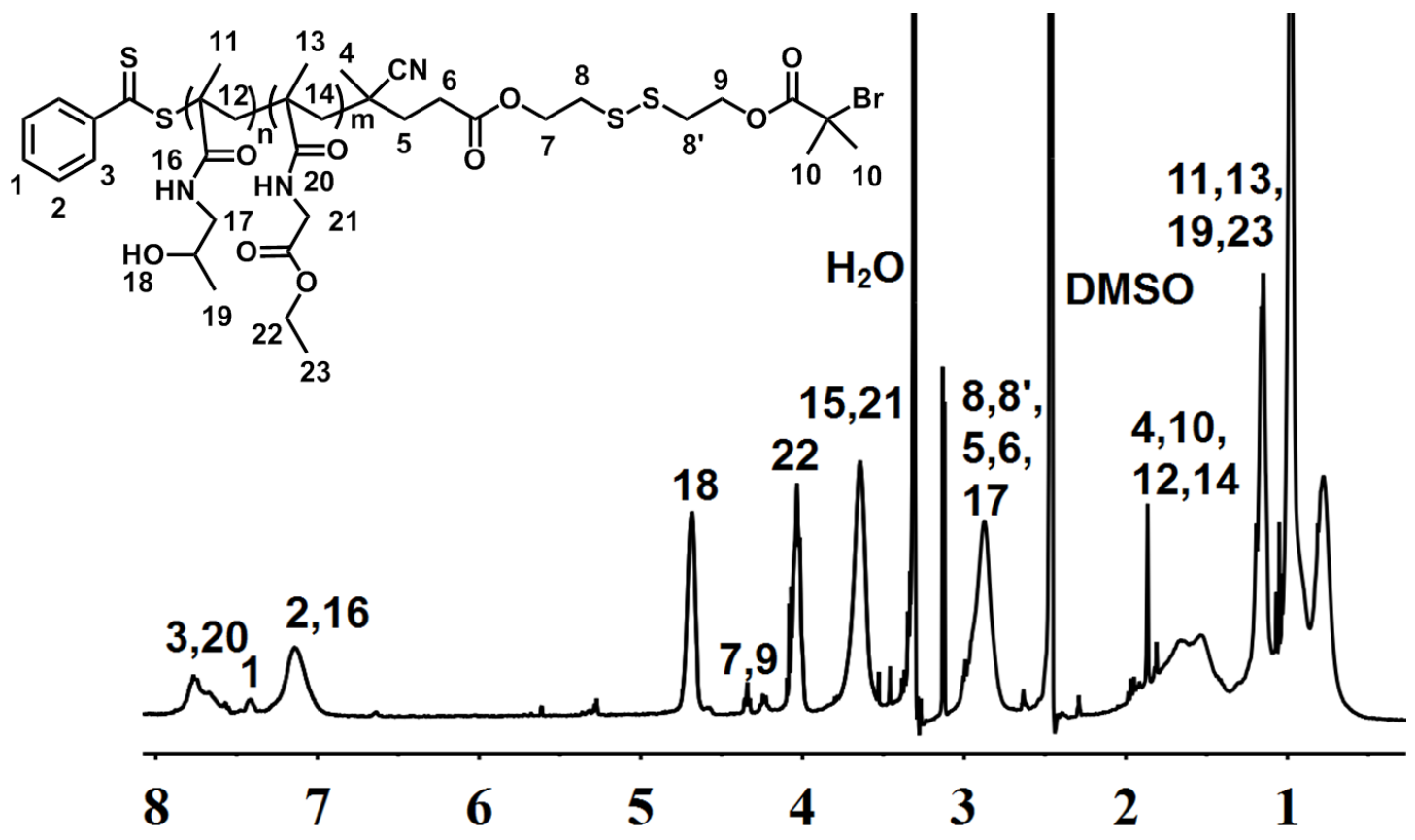

Figure S2. ${ }^{1} \mathrm{H}$ NMR spectrum of $\mathrm{P}\left(\mathrm{HPMA}_{36}-s t-\mathrm{EGMA}_{18}\right)-\mathrm{SS}-\mathrm{BBuBr}\left(d_{6}\right.$-DMSO). 


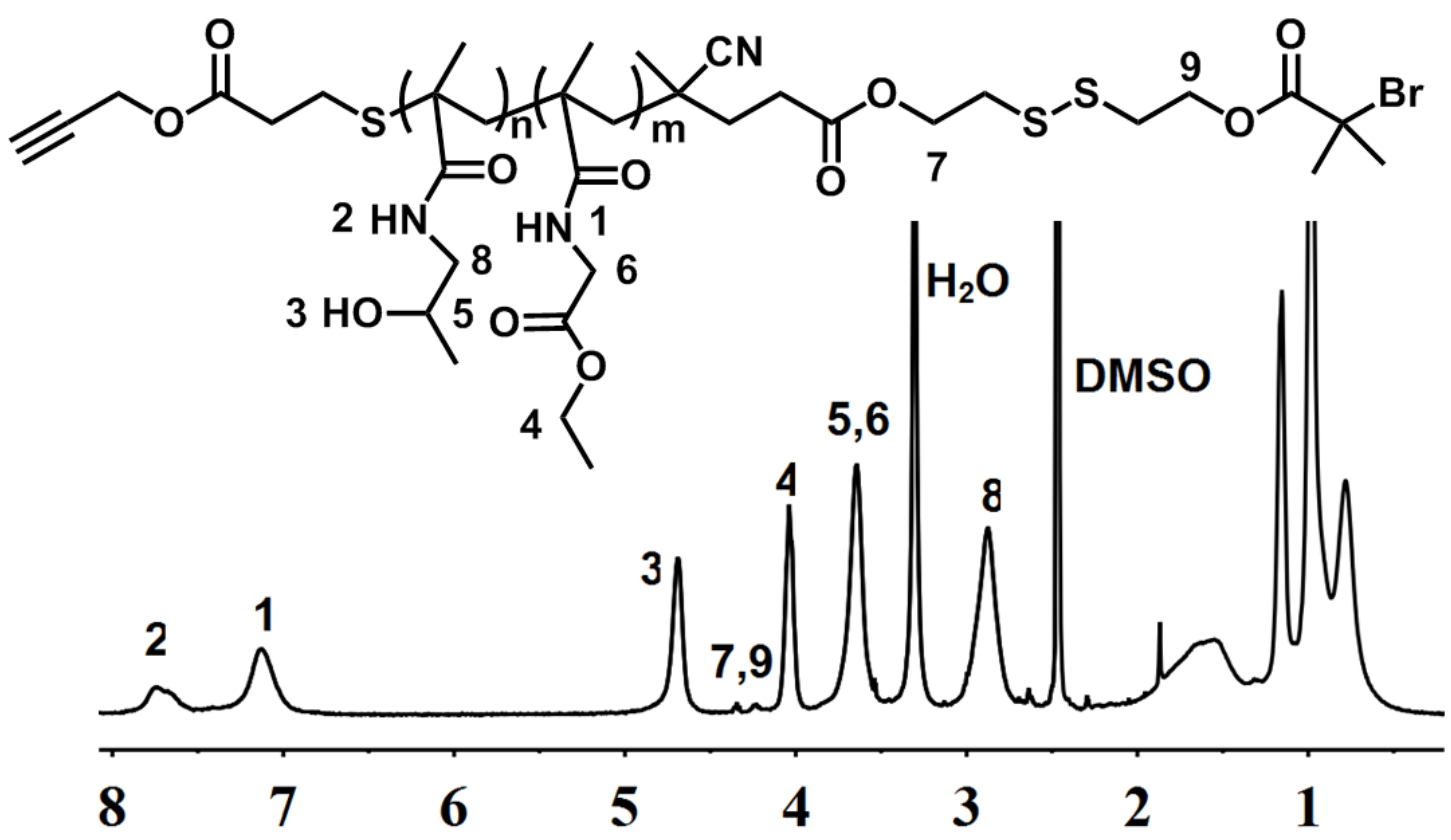

Figure S3. ${ }^{1} \mathrm{H}$ NMR spectrum of Alkyne-P(HPMA $\left.{ }_{36}-s t-\mathrm{EGMA}_{18}\right)-\mathrm{SS}-\mathrm{iBuBr}$ (d6-DMSO).

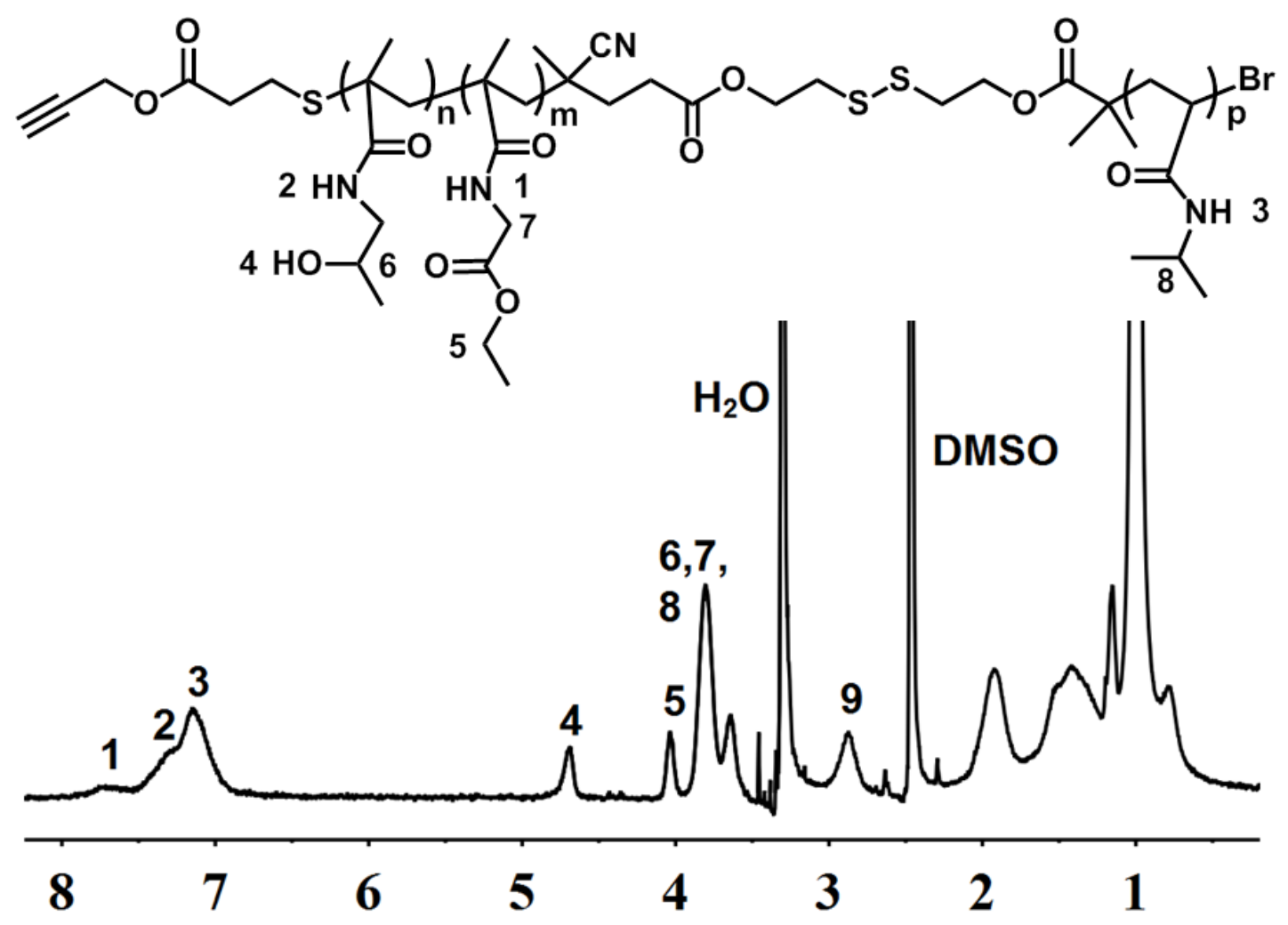

Figure S4. ${ }^{1} \mathrm{H}$ NMR spectrum of Alkyne-P(HPMA $\left.{ }_{36}-s t-\mathrm{EGMA}_{18}\right)-\mathrm{SS}-\mathrm{P}\left(\mathrm{NIPPAm}{ }_{192}\right)$ $\left(d_{6}\right.$-DMSO). 


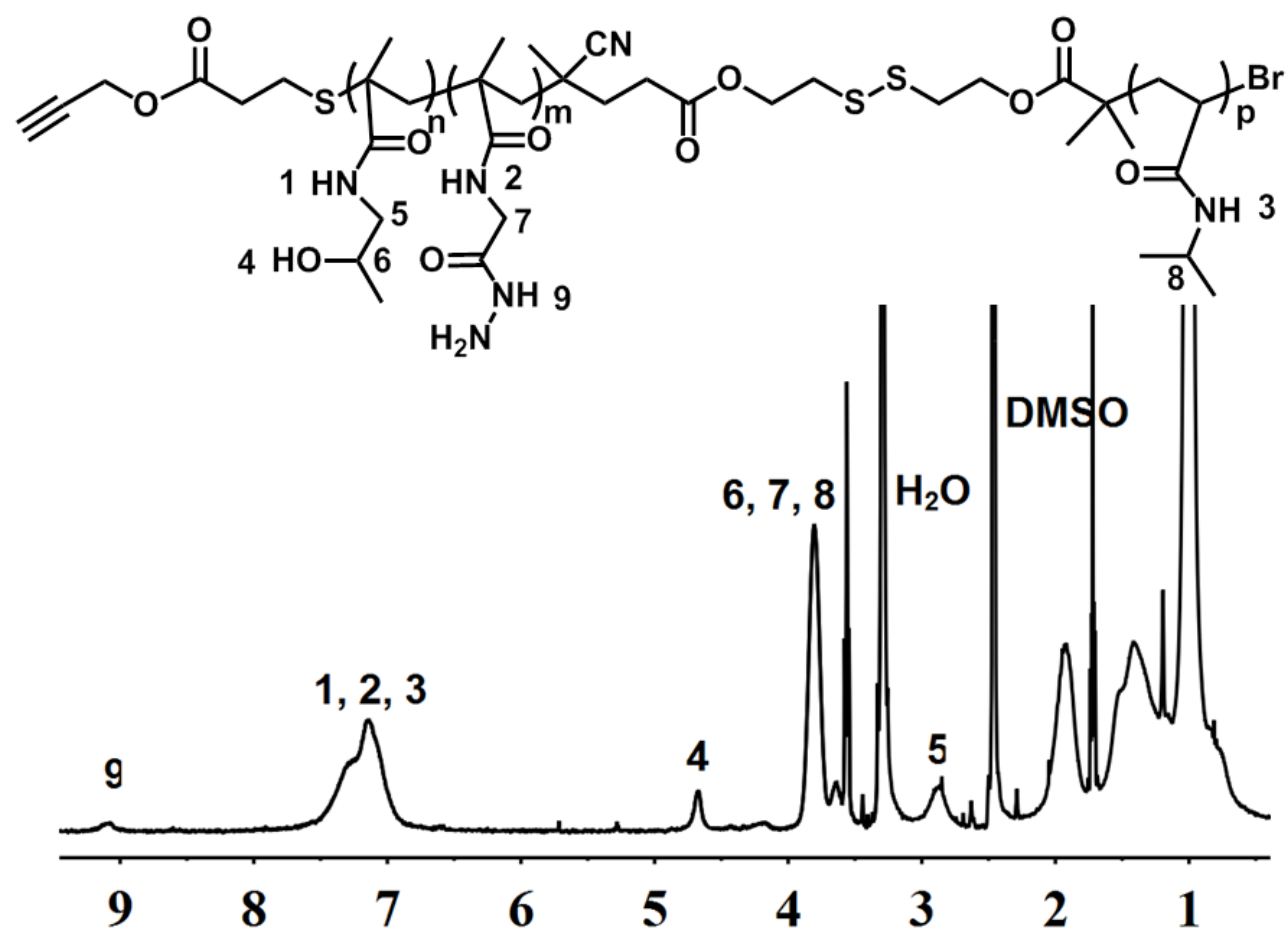

Figure S5. ${ }^{1} \mathrm{H}$ NMR spectrum of Alkyne-P(HPMA ${ }_{36}-$ st-(EGMA $\left.{ }_{18}-\left(\mathrm{NH}-\mathrm{NH}_{2}\right)_{13}\right)-\mathrm{SS}-\mathrm{P}$ (NIPAAm 192$)\left(d_{6}\right.$-DMSO).

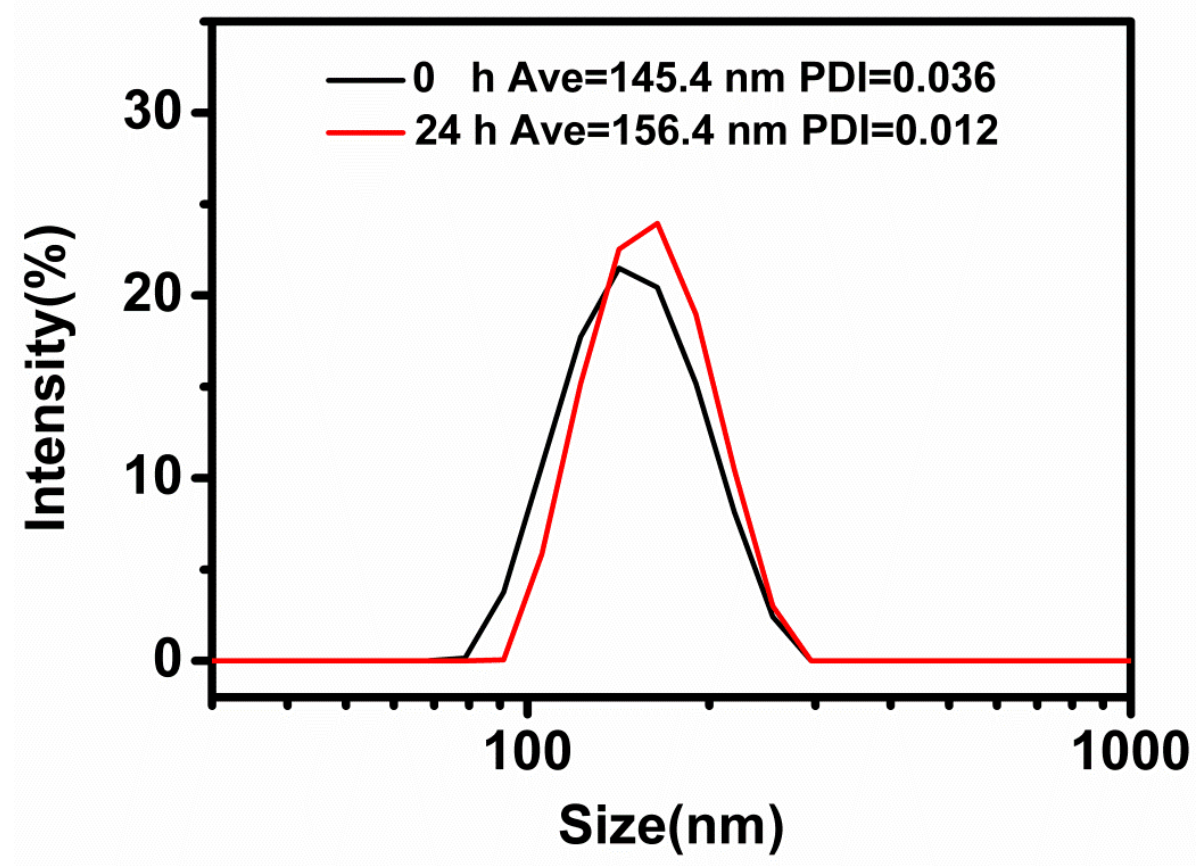

Figure S6. Time-dependent size distributions of the self-assembled micelles of Alkyne-P(HPMA $36-s t-\left(\right.$ EGMA $\left.\left._{18}-\mathrm{DOX}_{9}\right)\right)-\mathrm{SS}-\mathrm{P}\left(\mathrm{NIPAAm}_{192}\right)$ at a polymer concentration of $0.05 \mathrm{mg} / \mathrm{ml}$ in water at $37{ }^{\circ} \mathrm{C}$ determined by DLS. 

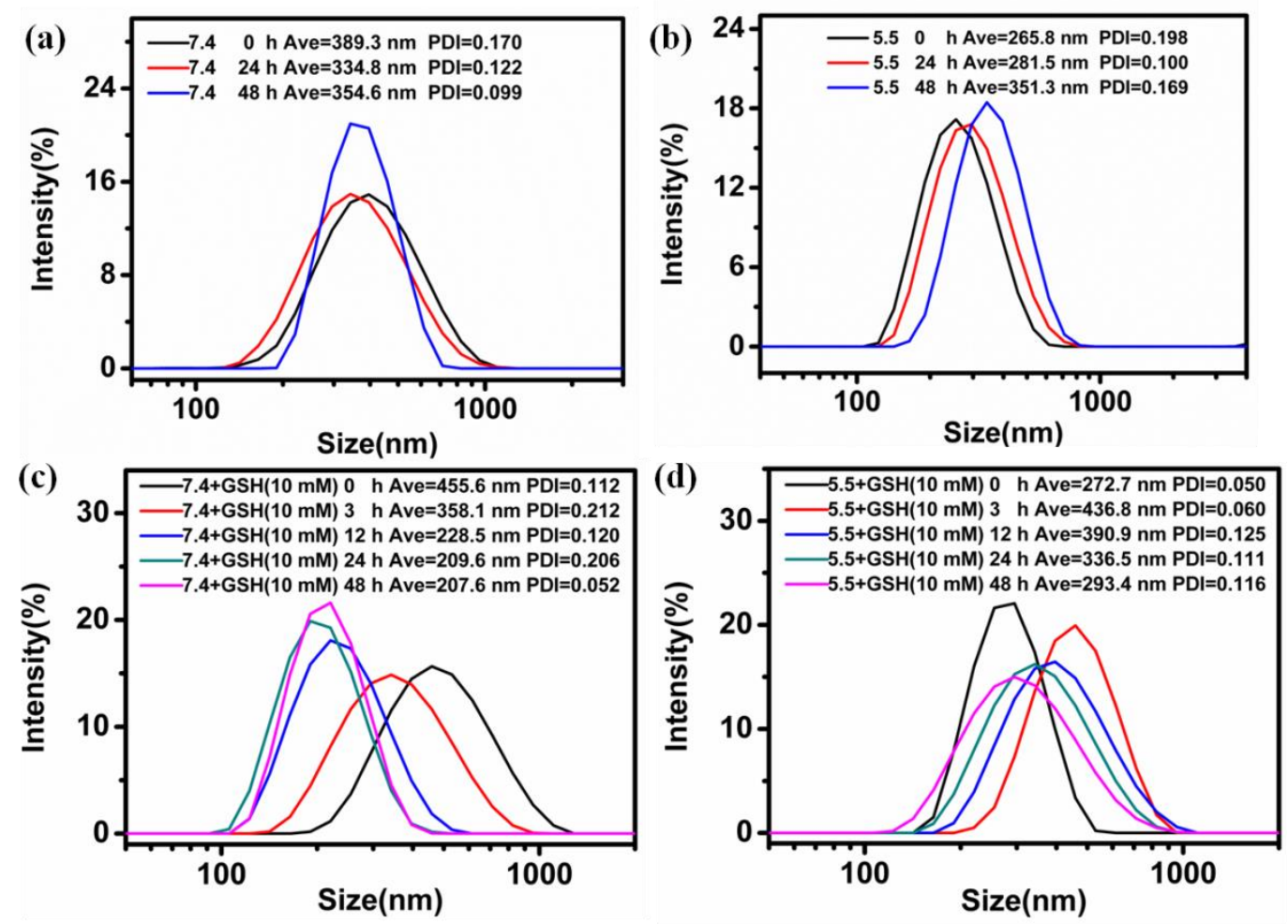

Figure S7. DLS-determined size distributions of the self-assembled micelles of

Alkyne-P(HPMA ${ }_{36}-s t-\left(\right.$ EGMA $\left.\left._{18}-\mathrm{DOX}_{9}\right)\right)$-SS-P(NIPAAm 192$)$ at a polymer concentration of $0.025 \mathrm{mg} / \mathrm{ml}$ in different media of phosphate buffer ( $\mathrm{PB}, \mathrm{pH} 7.4,10$ mmol), citrate buffer ( $\mathrm{pH} 5.5,10 \mathrm{mmol}$ ), phosphate buffer (PB, $\mathrm{pH} 7.4,10 \mathrm{mM}$ ) with $10 \mathrm{mM} \mathrm{GSH}$, and citrate buffer (pH 5.5, $10 \mathrm{mM}$ ) with $10 \mathrm{mM} \mathrm{GSH}$ at $37^{\circ} \mathrm{C}$ for various incubation periods. 


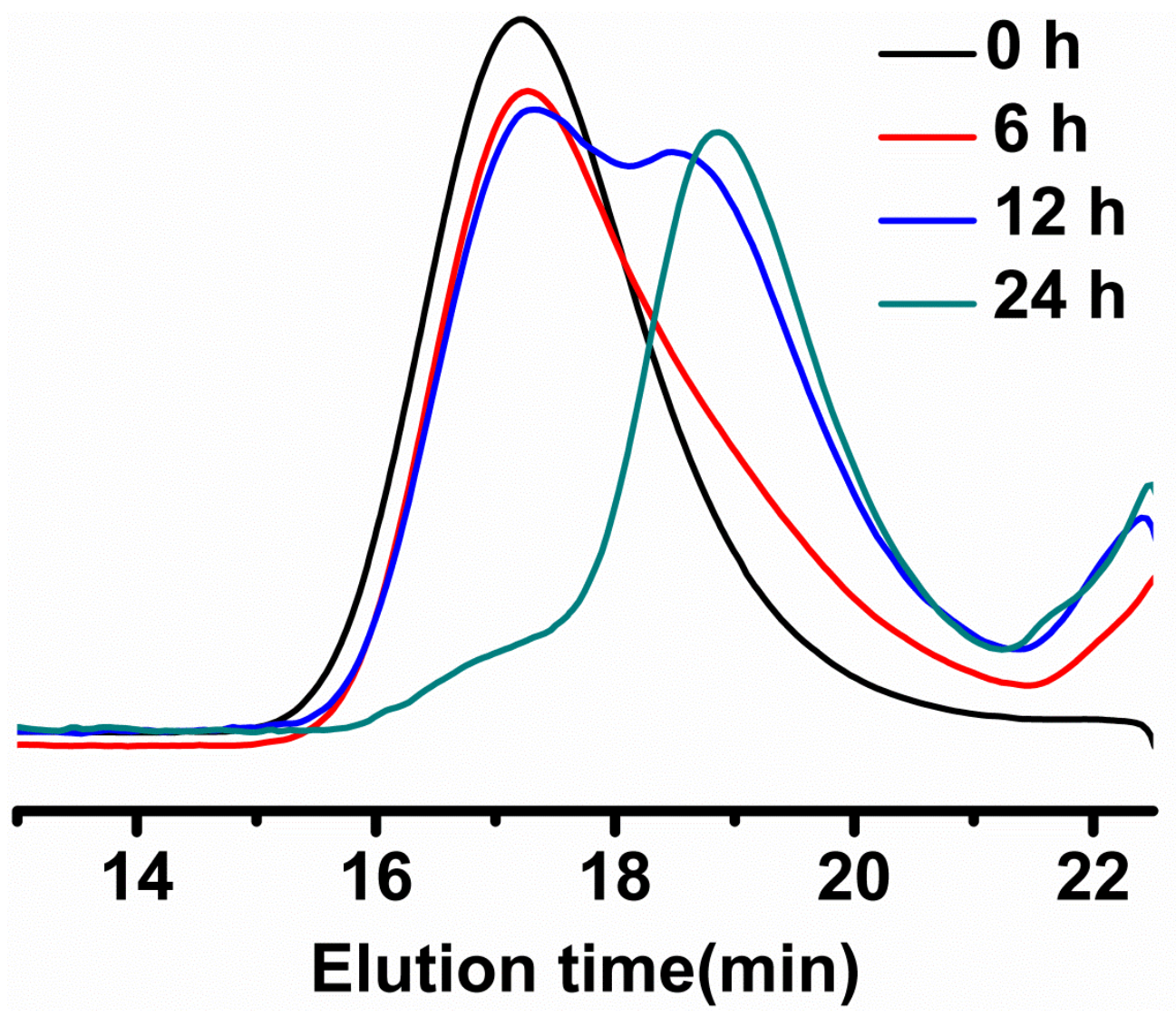

Figure S8. SEC-MALLS analysis of the degraded products of

Alkyne-P(HPMA ${ }_{36}-$ st-(EGMA $\left.\left.18-\mathrm{DOX}_{9}\right)\right)$-SS-P(NIPAAm $\left.{ }_{192}\right)$ incubated at $\mathrm{pH} 7.4$ and $37^{\circ} \mathrm{C}$ with $10 \mathrm{mM}$ GSH for various periods. DMF was used as the eluent. 


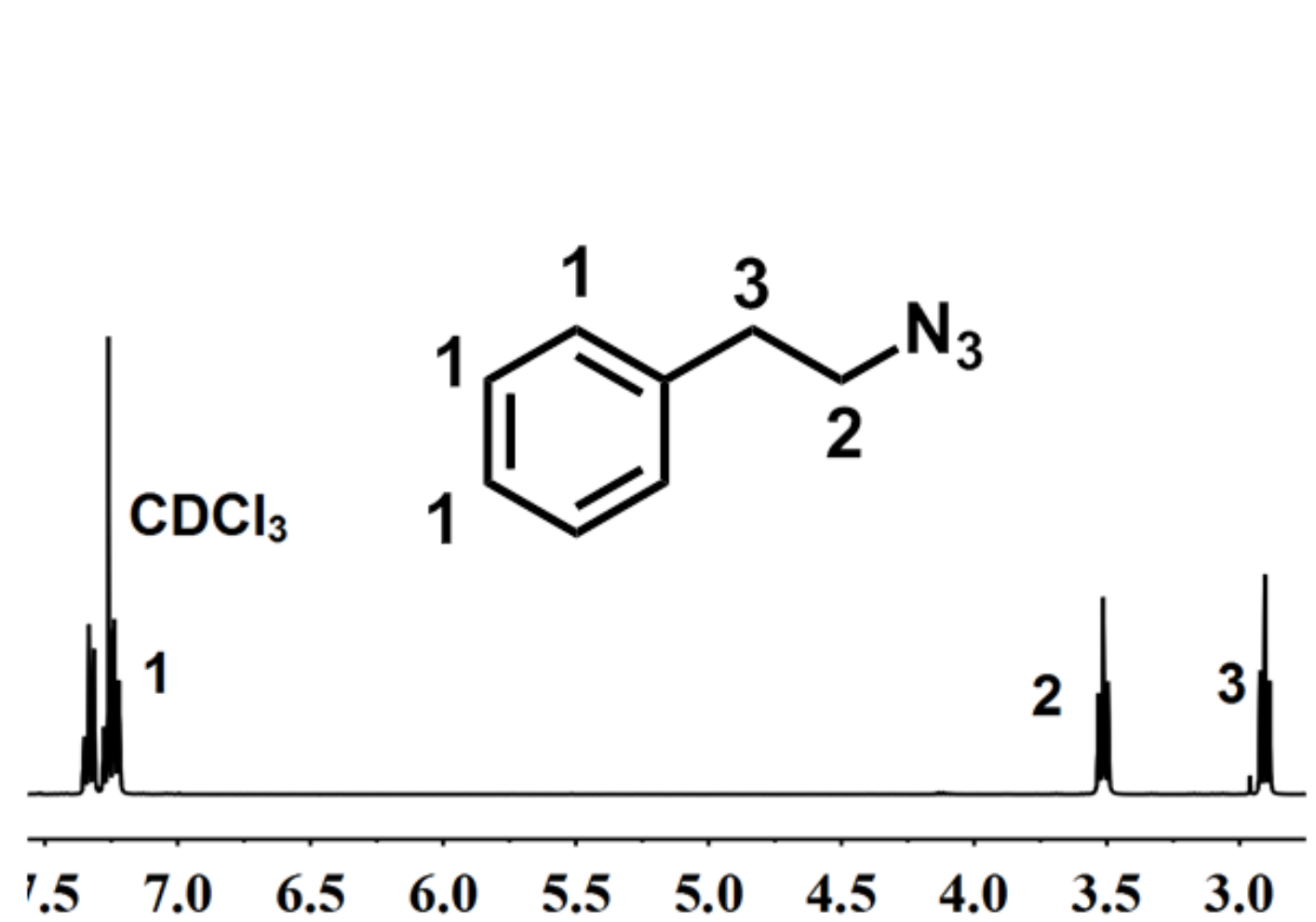

Figure S9. ${ }^{1} \mathrm{H}$ NMR spectrum of (2-Azidoethyl) benzene $\left(\mathrm{CDCl}_{3}\right)$.

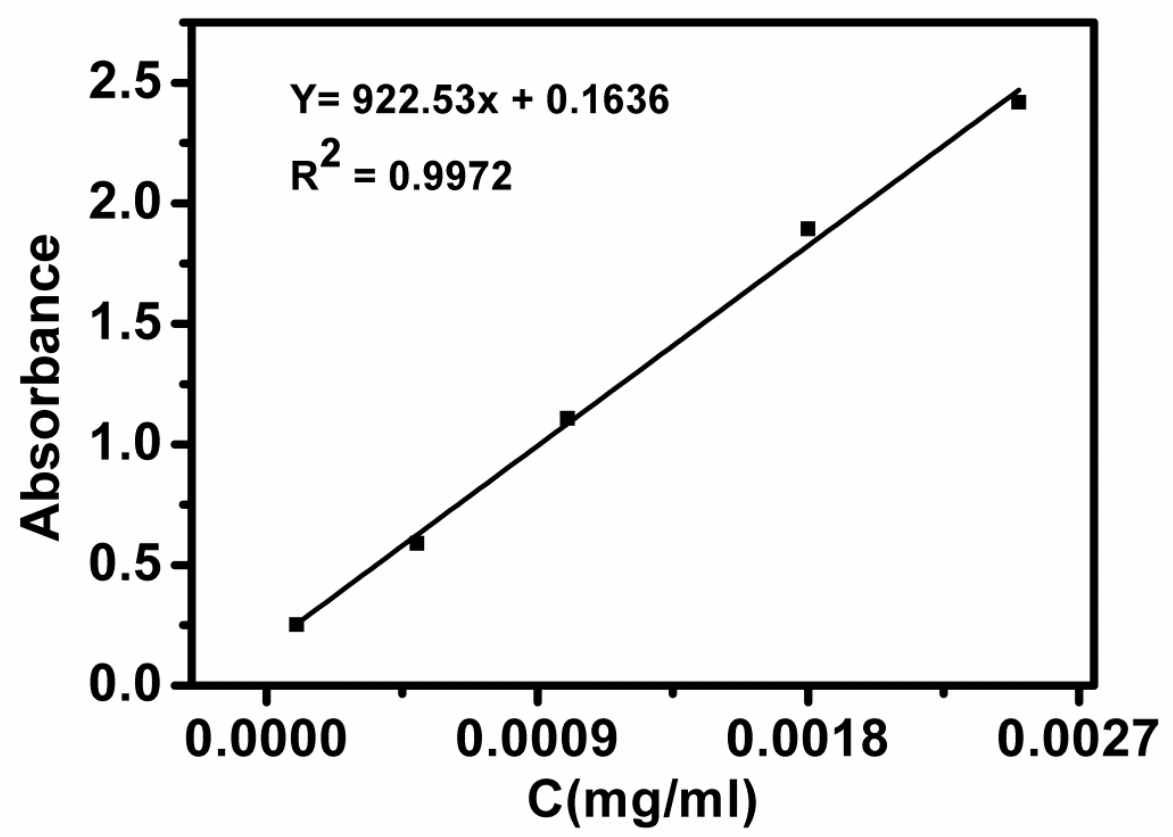

Figure S10. Standard curve plotted by the absorbance at $267 \mathrm{~nm}$ against various (2-Azidoethyl) benzene concentrations in DMF. 


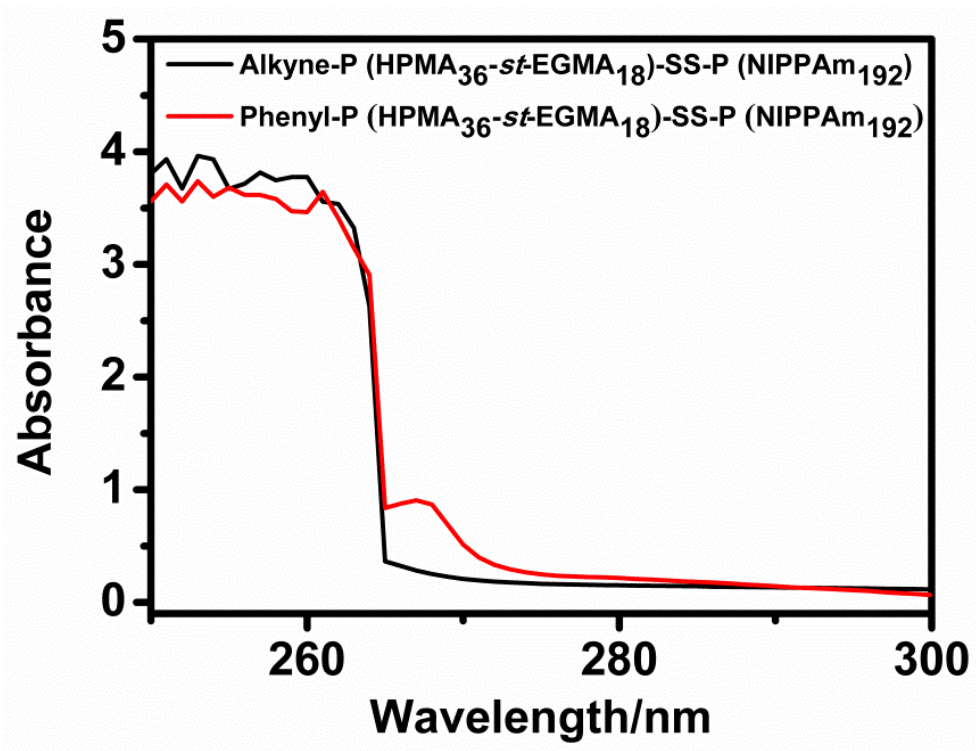

Figure S11. UV-Vis absorbance of

Alkyne-P(HPMA $36-$-st-EGMA 18$)-S S-P\left(N_{1 P A A m}{ }_{192}\right)$ and

Phenyl-P(HPMA ${ }_{36}-s t-$ EGMA $\left._{18}\right)$-SS- P(NIPAAm 192$)$ in DMF.

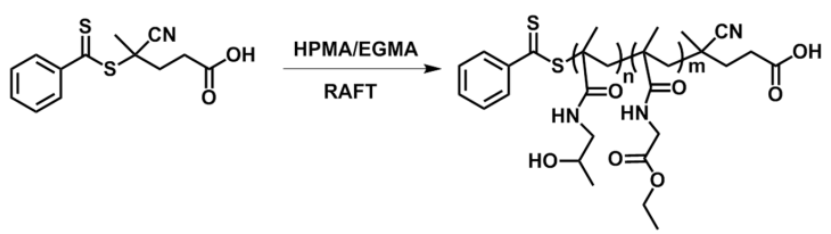

P(HPMA-st-EGMA)

Hydrazine hydrate

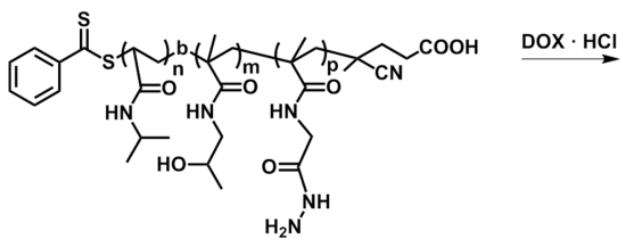

P(HPMA-st-(EGMA-NH-NH $\left.\left.{ }_{2}\right)\right)-b-P($ NIPAAm)

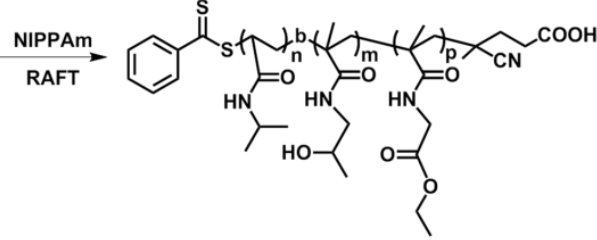

P(HPMA-st-EGMA)-b-P(NIPAAm)

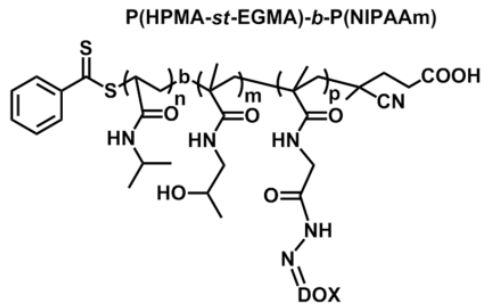

P(HPMA-st-(EGMA-DOX))-b-P(NIPAAm)

Scheme S1. Synthesis of P(HPMA-st-(EGMA-DOX))-b-P(NIPPAm). 
Table S1. Summarized molecular parameters of the synthesized HE-N polymer panel.

\begin{tabular}{|c|c|c|c|}
\hline Samples & $M_{\mathrm{n}}^{\mathrm{a}}(\mathrm{kDa})$ & $M_{\mathrm{n}}^{\mathrm{b}}(\mathrm{kDa})$ & $\mathrm{PDI}^{\mathrm{b}}$ \\
\hline P(HPMA $\left.38-s t-E_{1 M A} 19\right)$ & 8.68 & 10.00 & 1.14 \\
\hline 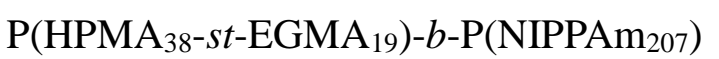 & 30.07 & 56.04 & 1.43 \\
\hline
\end{tabular}

${ }^{\mathrm{a}}$ Determined by ${ }^{1} \mathrm{H}$ NMR analysis.

${ }^{b}$ Determined by SEC-MALLS. 